\title{
The art and future of digital
}

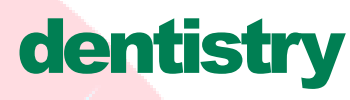

Georgi lliev

Department of Prosthetic dentistry,

Faculty of Dental Medicine, Medical University of Sofia

\section{Abstract}

The Digital Dentistry Market is driven by factors, such as achievement of higher capability for efficient care, delivered by various dentists across the globe. The increasing demand for better dentistry and for better aesthetic outcomes is a significant market trend. As the technology improves, modern units and systems are offered and vendors are working on extending core technologies to new applications and responding to emerging standards, business models, service delivery methods and other technological changes.

Current systems can help the clinician to provide smile designs that consider patients', sense of identity and selfesteem. Today, the use of new digital technologies can improve the communication process between specialists. Increasingly in frequency and comprehensive use of intraoral scanners and fast online exchange of data turned the conventional dental laboratory into a Virtual lab. The pre-visualisation of the final result can be a motivational key, not only to start the treatment, but also to keep the patient involved through out the process.

Combining modern digital technologies with the classic treatment rules can be used to achieve predictable esthetic results. Digital concepts, which can be applied very rapidly, can help the dentist and dental technician to achieve this goal in the most simplistic, practical and personalized way.

\section{Keywords: Digital dentistry, Smile design, Dental market}




\section{Background}

The aesthetic paradigm is part of the philosophicaltheory of the laws of beauty and its rational and emotional assessment. It regards man in a spiritual, social and biological aspect. The spiritual-social aspect refers to the person's personal qualities and public appearances. The biological aspect is manifested through the external appearance, i.e. through the architectonics of the human body. The combination of the characteristic aesthetic features and signs of architectonics determines the physical beauty of the body. One perceives the aesthetic and signs of the object through observation and immediately, without thinking or analyzing, one appreciates their physical beauty [1].

We form our first impressions based on facial appearance. There is a clear correlation between first impressions and significant social results. Appearance is vital, as some facial characteristics are particularly useful in targeting adaptive behavior, therefore, even a trace of these characteristics may create an impression [2]. The qualities revealed by facial signs, characterized by a specific identity, are hyperbolized in people whose appearance looks unusual.

The relationship between a first impression and facial expressions is of great scientific interest and is influenced by the increasingly widespread use of facial images on social media [3].

\section{The New Concept}

Complex cases with high aesthetic needs represent a challenge for clinicians. An interdisciplinary approach is vital to achieve the planned result. New technological devices are needed to facilitate the collaboration between the clinical team members and to develop a fluent and effective diagnostic and therapeutic pathway.

Through the large number of smile design's elements, as incisal edge, dominance, dental axis and shapes as sub elements, such as morphological details of each tooth,

it is possibly to establish, based on the dental scientific literature, which ones should be determined by the facial typology and which could visually represent the unique personality of each patient, beyond their personal preferences and expression's will [4].

Thus, for a standard practice, reproducible and accessible to all professionals, a concept for smile design customisation was elaborated. This holds true when the dentist first evaluates a new patient with aesthetic concerns, many critical factors may be overlooked. The verbal information exchange should be translated into a visual perception in order to get the patient and the dentist understand what exactly the final expectations should be at the end of the treatment. The basics means of this communication starts with a 3D preview of the design in the patients mouth (APT) even before the rest of the treatment is planned. At the end of the day no matter what clinical difficulties a dentist would face, how technically these problems would be solved, if the patient would not like the final aesthetic outcome, the treatment will be considered as a failure [5].

\section{The Digital Simplicity}

In the fifth dimension including personality traits on top of the previous aesthetic rules, makes a world of a difference when properly introduced to the algorithm. The computational mind is now fueled not only by the biological, structural, functional and aesthetic parameters but also variables related to personality. Dental technicians using the smile design software are able to perform facial reading, personality assessment and personal preferences evaluation of each patient and convert that information into mathematical language. Through pre-programmed algorithms initially 
a two-dimensional smile design is created. The software is capable to transform automatically this 2D smile design into a 3D customised model. The model generation is performed by custom 3D library. Every model is personalised according to the proposed teeth configuration [6].

\section{The Virtual Lab}

Increasingly in frequency and comprehensive use of intraoral scanners and fast online exchange of data turned the conventional dental laboratory into a Virtual lab. This represnts actually a virtual lab that converts the $2 \mathrm{D}$ design into $3 \mathrm{D}$, and creates a digital wax up immediately. The $2 \mathrm{D}$ is created by relating the facial perception and the personality of the patient to the smile design, by applying algorithms for computing the optimal combination of the incisal silhouette, tooth axis, dominance of the centrals and the combination of individual tooth shapes out of thousands of possibilities. It may sound complicated, however however it provides a great simplicity to the end users, the dentists and dental technicians [7]. (Figure 1)

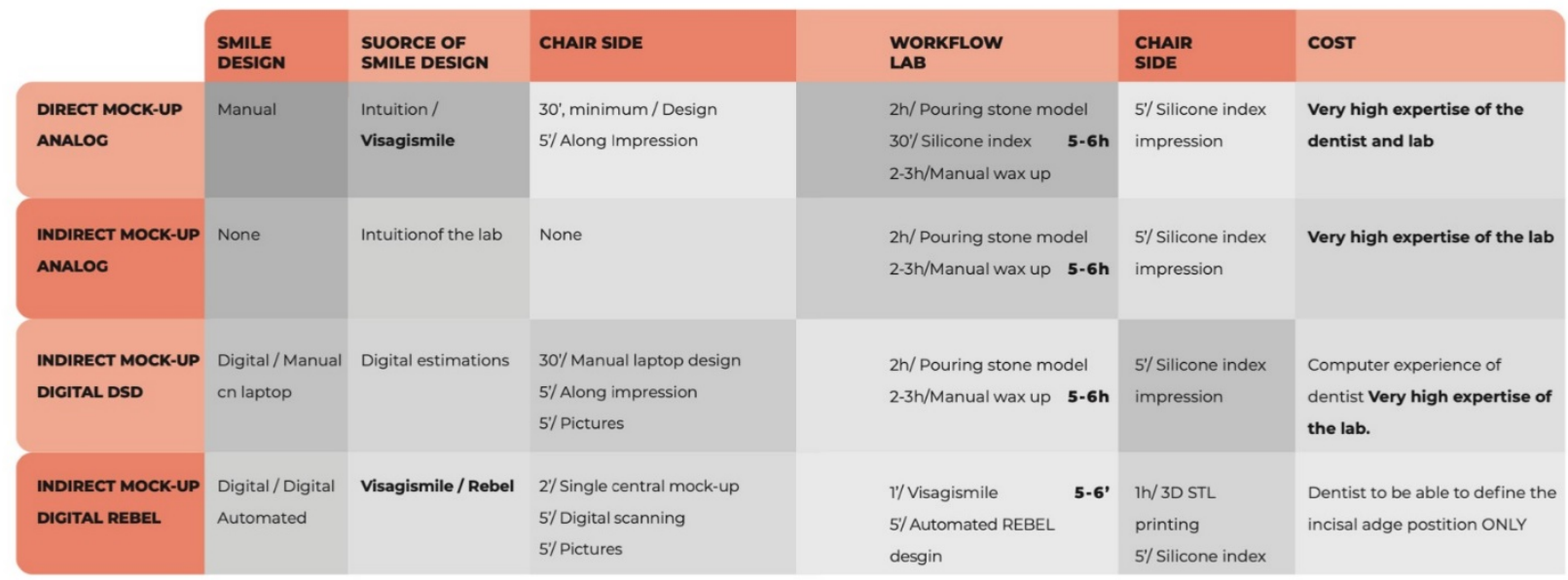

Figure 1. Comparison between different approaches for mock up, workflow, cost: analog v/s digital, direct $\mathrm{v} / \mathrm{s}$ indirect.

\section{The Ideal Treatment}

The ideal treatment can be mono professional approach or, better an interdisciplinary approach. The best aesthetic results largely depends on the ability of the members of the interdisciplinary team to work together. Efficient communication between team members can present a challenge due to the requirement for continuous communication between the different specialists. Prosthodontist, orthodontist, periodontist, and dental technician need to work together because understanding the various phases of the treatment is fundamental to achieving the desired result.

Today, the use of new digital technologies can improve the communication process between specialists. The pre visualisation of the final result can be a motivational key, not only to start the treatment, but also to keep the patient involved through out the process.

Digital smile design software could create top quality dental mockups quickly and easily. For dentists who need to plan their aesthetic cases it simplifies the prototyping process and makes it more predictable [8].

\section{Future is now}

It is not only creating the most personalized smile design thet is different and unique for every other patient, but also transforming all this data into a 3D wax up "stl" file.

"As one of the recognized global leaders in esthetic dental solutions we are 
now driving the development of digital esthetics. It is an exciting time to be in the dental industry." Mr. Ganley, Ivoclar Vivadent

\section{Adoption and Integration of Digital Dentistry}

A few years ago, digital dentistry in comparison with other industries, was extremely small in terms of the revenue generated and the potential market growth. Some of the technological advances were slow to be integrated in digital dentistry due to the relatively small financial input and global interest that is required for more efficient and improved digital dentistry. Fortunately the number of dentists adopting these technological advancements is growing nowadays.(Figure 2)

\begin{tabular}{|c|c|c|c|c|c|c|c|c|}
\hline$\underset{1}{\text { ACQUISITION }}$ & $\begin{array}{c}\text { DESIGN } \\
2\end{array}$ & $\begin{array}{c}\text { BRAIN STORM } \\
3\end{array}$ & $\begin{array}{c}\text { TEST DRIVE } \\
4\end{array}$ & $\begin{array}{c}\text { FUNCTION } \\
5\end{array}$ & $\begin{array}{c}\text { CLINICAL } \\
6\end{array}$ & $\begin{array}{c}\text { QUALTYY CONTROL } \\
7\end{array}$ & $\begin{array}{c}\text { MANUFACTURE } \\
8\end{array}$ & $\begin{array}{c}\text { CEMENTATION } \\
9\end{array}$ \\
\hline $\begin{array}{l}\text { Full face photo. } \\
\text { Personality } \\
\text { Mock-Up Central } \\
\text { Only } \\
\text { Intraoral Scan } \\
\text { Individual } \\
\text { requests }\end{array}$ & $\begin{array}{l}\text { Immediate R } \\
\text { 2D preview } \\
\text { Completely } \\
\text { Presonalised } \\
\text { Automated } \\
\text { 3D design } \\
\text { 3D Preview } \\
\text { Download STL file } \\
\text { ready for printing }\end{array}$ & $\begin{array}{c}\text { Design preview } \\
\text { CLoud } \\
\text { Patient is involved } \\
\text { Easy to share } \\
\text { Help section } \\
\text { Email, } \\
\text { contact } \\
\text { professional }\end{array}$ & $\begin{array}{l}\text { Motivational Mock- } \\
\text { Up } \\
\text { Silicon Stent } \\
\text { Mock-Up up shell } \\
\text { Strategy } \\
\text { Studio Photography } \\
\text { Personality Types } \\
\text { Treatment planning } \\
\text { Patient } \\
\text { communication } \\
\text { Conclusion }\end{array}$ & $\begin{array}{c}\text { Deprogrammer } \\
\text { Only buccal }\end{array}$ & $\begin{array}{l}\text { Verify aesthetic } \\
\text { result } \\
\text { Prep analisys } \\
\text { Prep through APT } \\
\text { Tissue control } \\
\text { Digital import } \\
\text { Direct Flow }\end{array}$ & $\begin{array}{c}\text { Retreatment } \\
\text { Protocols }\end{array}$ & $\begin{array}{c}\text { Rebel 3D software } \\
\text { Exocad } \\
\text { 3 Shape } \\
\text { Zirkonzhan } \\
\text { 3D printing } \\
\text { In-house mill } \\
\text { Outsuorce mill } \\
\text { Materials }\end{array}$ & $\begin{array}{l}\text { Materials } \\
\text { Isolation } \\
\text { Occlusion } \\
\text { Hygiene } \\
\text { Quality Control } \\
\text { Follow up } \\
\text { Maintaining }\end{array}$ \\
\hline
\end{tabular}

Figure 2. Complete esthetic digital dentistry workflow, most important stages.

\section{Drivers and Restraints for Digital Dentistry Market}

The Digital Dentistry Market is driven by factors, such as achievement of higher capability for efficient care, delivered by various dentists across the globe. The increasing demand for better dentistry and for better aesthetic outcomes is a significant market trend. As disposable income is increasing in the developed and developing economies, patients are willing to invest in their dental health and aesthetics. However, the cost associated with digital dentistry is a restraining factor in the global Digital Dentistry Market.

The Digital Dentistry Market is growing considerably in the past 10 years, including 3D printing and scanning services, software, hardware and materials. The main competitive factors are features, reliability, brand name recognition, distribution network, customer service, and price. The digital dental CAD/ CAM systems, scanner markets are characterized by changing customer needs.

\section{Change relates to efficiencies provided by the technology.}

As the technology improves, modern units and systems are offered and vendors are working on extending core technologies to new applications and responding to emerging standards, business models, service delivery methods and other technological changes.

Success depends on the ability to enhance existing products and services. The existing worldwide trends in 3D printing revenue opportunities for the period 2015-2027 shows that software products combined with online services revenue opportunity is expected to reach $\$ 9,51$ billion in 2027 as new products and services are introduced on a timely basis. Vendors seek to provide cost-effective solutions. The systems finds application in the dental medicine, in particular in the aesthetic dental treatment.(Figure 3) 

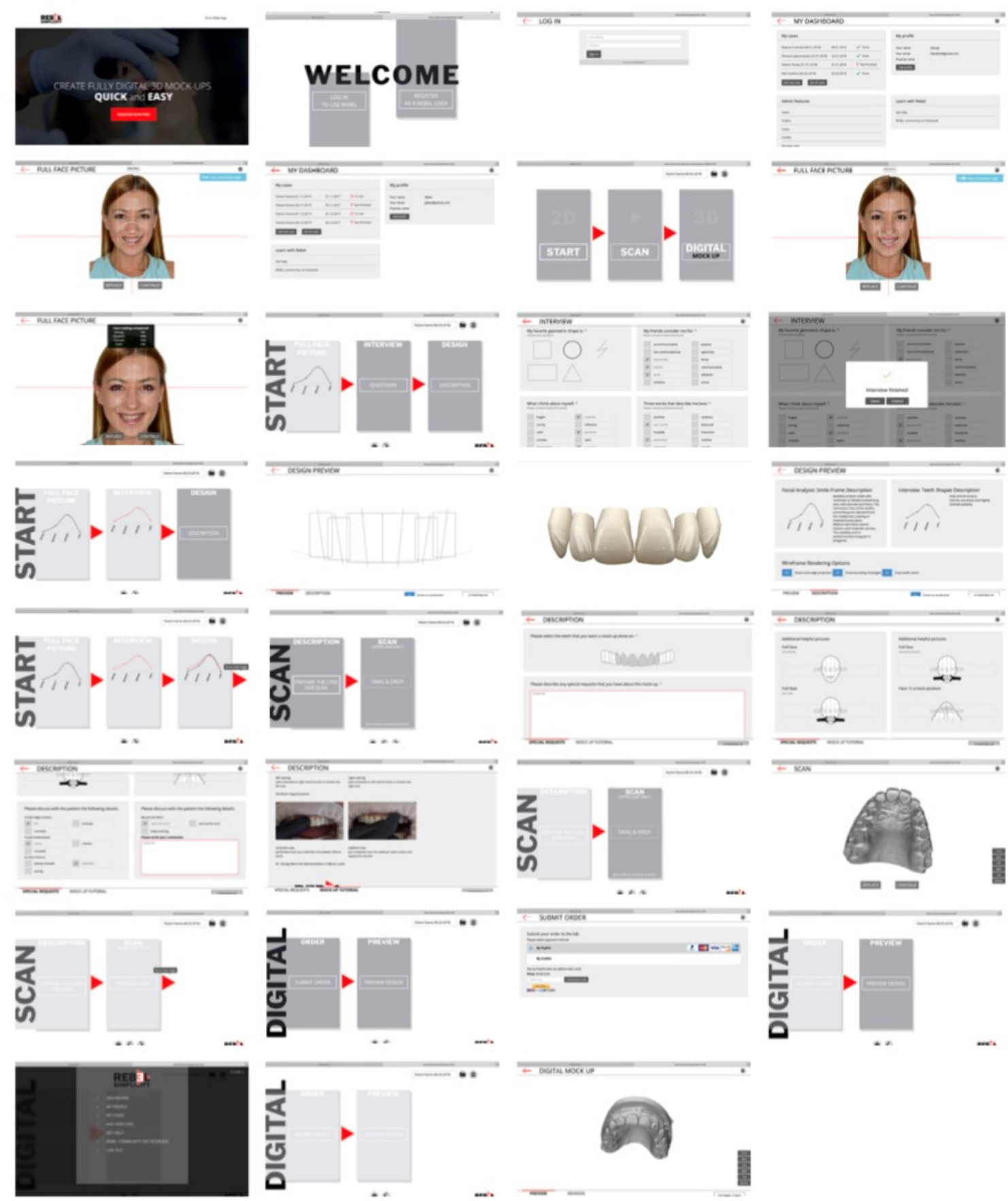

Figure 3. User perspective interface of a smile design software.

The purpose of the invention is to create a system for production of three- dimensional digital dental models using an integrated methodology whereby the personal facial features, and personal preferences of the patient are transmitted to their corresponding realistic three-dimensional teeth shapes [9]. (Figure 4) 


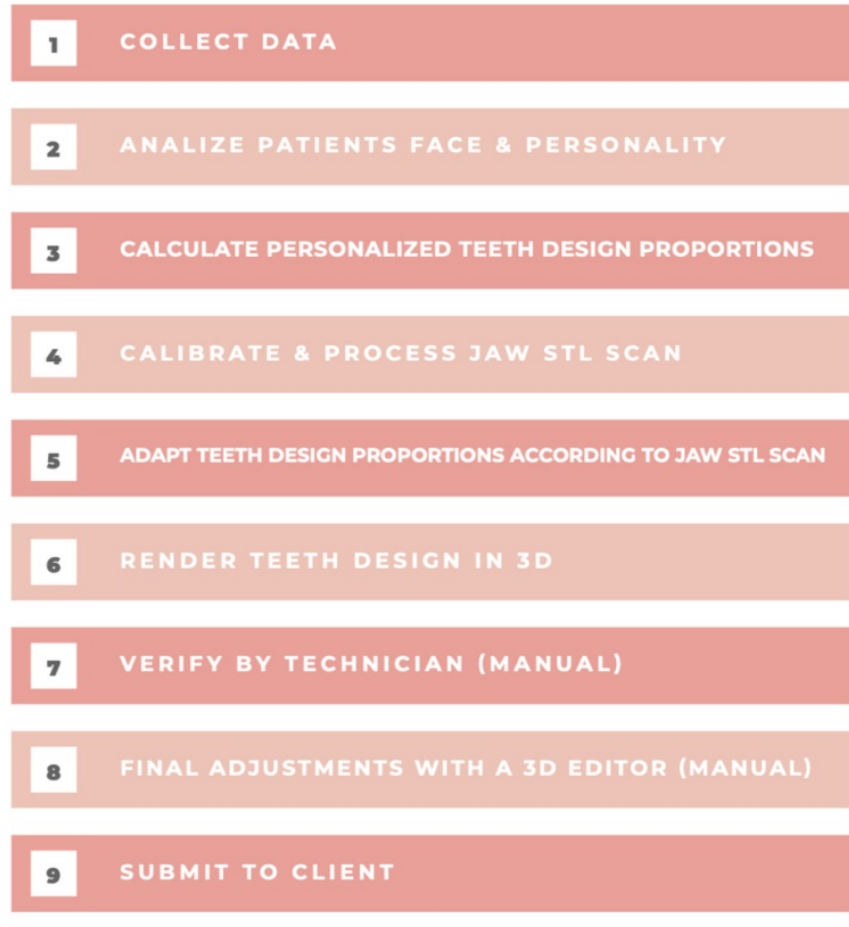

Described in detail in international patent application No PCT/BC2018000024.

Figure 4. The system for production of three-dimensional digital dental models using an integrated methodology whereby the personal facial features, and personal preferences of the patient are transmitted to their corresponding realistic three-dimensional teeth shapes, block diagram.

\section{Conclusion}

Currently, software can help the clinician to provide smile designs that consider patients', sense of identity and self-esteem. Combining modern digital technologies with the classic treatment rules can be used to achieve predictable esthetic results. Digital concepts, which can be applied very rapidly, can help the dentist and dental technician to achieve this goal in the most simplistic, practical and personalized way.

\section{References}

1. G. Gurel, B. Paolucci, G. Iliev, et al. The Art and Creation of a Personalized Smile: Visual Identity of the Smile (VIS). QDT; 2019: 31-48

2. Zebrowitz, L., Montepare, J. Social Psychological Face Perception: Why Appearance Matters. Soc Personal Psychol Compass. 2008; (3): 1497. doi:10.1111/j.1751-9004.2008.00109.x.

3. Richard J.W. Vernon et Al. Modeling first impressions from highly variable facial images. 2014; www.pnas.org/cgi/doi/10.1073/pnas.1409860111

4. The art of a personalized smile design - G. Gurel, B. Paolucci, G. Iliev, et. al; Clinical MastersTM; Esthetic and Restorative Dentistry, 2020; 16-23 
5. Gurel, G, Morimoto, S, Calamita M, Coachman Ch, Sesma N. Clinical Performance of Porcelain Laminate Veneers: Outcomes of the Aesthetic Pre-evaluative Temporary (APT) Technique. The International journal of periodontics \& restorative dentistry.2012;(32):625-35.

6. G. Gurel, B. Paolucci, G. Iliev, et. al. The fifth dimension in esthetic dentistry. The International Journal of Esthetic Dentistry, 2021;(16): 2-24.

7. Coachman Ch, Calamita M, Sesma N. Dynamic documentation of the smile and the 2D/3D digital smile design process. The International Journal of Periodontics and restorative dentistry, 2017;(37):183-193

8. G. Iliev, G. Romeo. Harmony of smile design in the facial context. The International Journal of Esthetic Dentistry, 2020;(15):1:1-16.

9. G. Iliev, D. Filtchev, B. Yankov et al. System for production of three-dimensional digital dental models. International application published under the Patent Cooperation Treaty (PCT); WO 2019/218031

\section{Corresponding author: \\ Georgi Veselinov Iliev \\ Department of Prosthetic Dentistry \\ Faculty of Dental Medicine \\ Medical University of Sofia \\ 1 St.Georgi Sofiiski str. \\ 1431 Sofia, Bulgaria \\ ilievdent@gmail.com}

